Hispania, 2016, vol. LXXVI, $\mathrm{n}^{\circ}$. 253, mayo-agosto, págs. 323-354

ISSN: 0018-2141, e-ISSN: 1988-8368, doi: 10.3989/hispania.2016.010

\title{
La carrera de un mercader judeoconverso en el Nápoles español. Ne- gocios y relaciones políticas de Miguel Vaaz (1590-1616)*
}

\author{
Benedetta Crivelli \\ Università degli Studi di Padova \\ benedettamaria.crivelli@unipd.it \\ Gaetano Sabatini \\ Università degli Studi Roma Tre \\ gaetano.sabatini@inwind.it
}

RESUMEN: Este ensayo profundiza en algunos aspectos de la actividad en Nápoles del mercader y banquero judeoconverso de origen portugués Miguel Vaaz (1550 ca. - 1623). Más precisamente, en la primera parte del ensayo, se presentan los resultados de un análisis sistemático de la documentación contable proveniente de los archivos de los antiguos bancos públicos napolitanos (actualmente conservada en el Archivio Storico del Banco di

* Abreviaturas utilizadas: AGS (Archivo General de Simancas), ASBN (Archivio Storico del Banco di Napoli), BNM (Biblioteca Nacional de Madrid); BNN (Biblioteca Nazionale di Napoli). Las cantidades de grano están expresadas en carra (singular carro) y tomoli (singular tomolo) con la equivalencia 1 carro $=36$ tomoli $=801,9 \mathrm{~kg}$. En el caso de mercancías como seda y especias se usaban los cantari (singular cantaro) y rotoli (singular rotolo), con la equivalencia 1 cantaro $=100$ rotoli $=89.1 \mathrm{~kg}$. Todas las cifras se indican en ducados napolitanos, 1 ducado $=10$ carlinos, con aproximación por exceso de las fracciones. Véase MARTINI, 1883: 394-396. Los autores han escrito juntos la Introducción y las Conclusiones del ensayo, Benedetta Crivelli ha escrito el epígrafe 2 y Gaetano Sabatini el epígrafe 3. Para la redacción de este ensayo, Benedetta Crivelli se ha beneficiado de la "Borsa di Studio per Giovani Ricercatori Luigi De Rosa 2014» del Instituto Banco de Nápoles - Fundación, y Gaetano Sabatini del proyecto «El papel de los mercados financieros y la gestión de los negocios mercantiles en las economías de la Monarquía Hispánica, ca. 1550-1650» (referencia: HAR201345788-C4-2-P). Los autores agradecen al personal del Archivio Histórico del Banco de Nápoles la ayuda ofrecida durante el desarrollo de la investigación; un sentido agradecimiento además a Yasmina Rocío Ben Yessef Garfía de la Universidad Pablo de Olavide de Sevilla por las informaciones relativas a la indicación de las cuentas de Miguel Vaaz en el Banco Spirito Santo durante los años 1601-1607. 
Napoli). Esta documentación ha permitido reconstruir no solo las actividades comerciales y financieras de Miguel Vaaz para los años 1593-1610, sino también su extraordinaria capacidad de crear una red de relaciones con las elites económicas y politicas del reino, hasta alcanzar, en los años del gobierno en Nápoles del virrey VII conde de Lemos, 1610-1616, el auge de su poder. A los conflictos que acompañaron esta trayectoria, se dedica la segunda parte del ensayo, con particular referencia al enfrentamiento que en el bienio 1614-1615 opuso el virrey conde de Lemos a una parte de la aristocracia del reino. Las vicisitudes de Miguel Vaaz se pueden considerar como ejemplos de la importancia del papel que los mercaderes y banqueros judeoconversos desarrollaron dentro de la monarquía española en la primera etapa de la edad moderna.

Palabras Clave: Monarquía Española; Reino de Nápoles; Edad Moderna; Historia Financiera; Bancos Públicos; Comunidades de Judeoconversos.

The career of a «Judeoconversos» merchant Banker in Spanish Naples. Business and political network of Miguel Vaaz (1590-1616)

ABSTRACT: This essay aims to investigate some aspects of the activity of the Portuguese «Judeoconverso» merchant-banker Michele Vaaz (1550 ca. - 1623), in Naples. More specifically, in the first part of the essay we presented the results of a systematic analysis of original documents of the ancient public banks of Naples (today conserved in the Archivio Storico del Banco di Napoli). These documents permit us to reconstruct the commercial and financial activities of Michele Vaaz from 1595 to 1610. Specific attention has been given to the ones that led Vaaz to establish a network of relationships within the local and central political elites of the kingdom and to reach, during the years of the VII Count of Lemos'rule, the peak of the power. That peak was achieved with conflicts and tensions that are described in the second part of the essay, dwelling in particular on an episode placed between 1614 and 1615. The importance and weight that the "Judeoconversos» Portuguese merchants-bankers new Christian had within the system of power of the Spanish monarchy during the XVII century explains the illustrative value of the history of Miguel Vaaz, marked by a constant confrontation with the centre of power and the local elites.

KEY WORDS: Spanish Monarchy; Kingdom of Naples; Early Modern History; Financial History; Public Banks; «Judeoconverso» Communities.

\section{INTRODUCCIÓN}

La figura del mercader y banquero judeoconverso de origen portugués Miguel Vaaz, que desarrolla su actividad en el reino de Nápoles a partir de la mitad de los años 80 del siglo XVI, ha sido objeto de recientes investigacio- 
nes, gracias al descubrimiento de nuevas fuentes documentales y dentro de un renovado interés historiográfico sobre las comunidades judeoconversas en la monarquía. Algunos estudios de los últimos años han permitido reconstruir la trayectoria de la comunidad de los cristãos novos portugueses de Nápoles en los siglos XVI y XVII, partiendo de las vicisitudes de su principal exponente, concretamente Miguel Vaaz, quien mediante la gestión de actividades comerciales y financieras alcanzó una posición de altísimo prestigio en la corte del virrey, el VII conde de Lemos, entre 1610 y 1616, para ser después perseguido en los años del virreinato del duque de Osuna, entre 1616 y 1620 , hasta su muerte en $1623^{1}$. Análogamente, en las generaciones siguientes, se ha estudiado el proceso de incorporación del entorno familiar de Miguel Vaaz y de sus descendientes al cuerpo de los llamados togados, los aristócratas magistrados de los mayores tribunales del reino, hasta el proceso inquisitorial que les afectó en los años 50 y 60 del siglo XVII, marcando su definitiva decadencia social ${ }^{2}$.

Situándose en la estela de la más reciente producción historiográfica sobre el tema, en primer lugar el presente estudio reconstruye más exhaustivamente las actividades comerciales y financieras de Miguel Vaaz en Nápoles; para alcanzar este objetivo, se ha realizado una investigación en las fuentes documentales pertenecientes a los antiguos bancos públicos napolitanos, actualmente conservadas en el Archivo Storico del Banco di Napoli, hasta ahora nunca utilizadas en relación a las actividades del mercader y banquero judeoconverso ${ }^{3}$.

El tipo de documento consultado ha sido ante todo el llamado giornale copiapolizze, el registro contable en el que se anotaban las libranzas, es decir, las órdenes de ingreso o de pago que los depositarios presentaban al banco cada día, a favor de sí mismos o de otros; se han consultado también las series de las pandette, es decir, de los registros que contenían los nombres de todos

1 SABATINI, 2010; ID. 2012, HUERGA CRIADO, 2012.

2 Noticias anteriores a los estudios de Huerga Criado y Sabatini sobre Miguel Vaaz en CONIGLIO, 1955; SIRAGO, 1986; ID. 1987; BELLI, 1990; SCARAMELLA, 2003; entre las fuentes antiguas la principal es el manuscrito de Domenico Confuorto, Notizie d'alcune famiglie popolari della Città e del Regno di Napoli, divenute riguardevoli per causa di ricchezze, o dignità, Napoli 1693, BNN, Manoscritti, X A 15 (otra copia en I D 5), cc. 127r-128v. A pesar del título prometedor, no aporta nuevos datos el reciente volumen The New Christians of Spanish Naples, 1528-1671. A Fragile Elite (MAZUR, 2013) que inexplicablemente, además de no incluir nueva documentación, no tiene en cuenta ni cita los últimos estudios publicados sobre este tema.

3 Se trata del Banco della Pietà (1539-1808), Banco dei Poveri (1563-1808), Banco dell'Annunziata (1587-1702), Banco di Santa Maria del Popolo (1589-1808), Banco dello Spirito Santo (1590-1808), Banco di S.Eligio (1592-1808), Banco di S. Giacomo e Vittoria (1597-1809), Banco del Salvatore (1640-1808). 
los depositarios del banco, con la indicación de las páginas del libro mayor de caja donde se registraban las cuentas de cada uno ${ }^{4}$.

Dada la gran cantidad de documentación conservada en este archivo, la investigación se ha centrado en las cuentas que Miguel Vaaz tenía en dos de los ocho bancos públicos napolitanos, el Banco dello Spirito Santo y el Banco di San Giacomo e Vittoria (habitualmente citado como Banco San Giacomo), en donde el mercader judeoconverso realizaba la mayor parte de sus actividades financieras. En concreto, el archivo del Banco del Spirito Santo es el más completo: ha sido posible consultar los giornali copiapolizze de los años 1593, 1595, 1602, 1603, 1604 (todos en un único volumen) y 1607 (en dos volúmenes); datos significativos también en las pandette del Banco del Spirito Santo para los años 1600-1607. En cambio, la documentación del Banco San Giacomo es más incompleta: concretamente se han consultado los giornali copiapolizze de los años 1601 (segundo semestre), 1602 (segundo semestre), 1603 (primer semestre), 1605 (solo los meses de junio y julio) y 1610 y 1616 (ambos en un único volumen $)^{5}$.

El análisis de esta documentación contable indica claramente el carácter ascendente de la trayectoria social de Miguel Vaaz, quien durante el primer decenio del siglo XVII se acercó mucho al poder español en Nápoles, del que llegó a ser parte orgánica. Precisamente por este motivo, el análisis que este ensayo propone se ha completado con el estudio de algunos aspectos de la relación de Miguel Vaaz con el poder político y de las tensiones que esta relación generó, sobre todo en la etapa final de la permanencia en Nápoles del VII conde de Lemos, quien abandonó el reino en 1616.

La red de hombres de negocios dentro de la cual se movió Miguel Vaaz se compuso en primer lugar de sus familiares y de miembros de otras familias de judeoconversos, como ya se ha reconstruido en anteriores estudios ${ }^{6}$, pero como el principal objetivo que movió toda su actividad fue claramente la consecución de una completa asimilación en el seno de las élites del Nápoles español, sus relaciones salieron rápidamente del estrecho circuito de los judeoconversos, para acercarse a los más altos representantes del gobierno español en Ná-

4 Sobre el origen y funciones de los bancos públicos napolitanos, en concreto en referencia a las actividades de depósito y de cambio generalmente desarrolladas por Miguel Vaaz, véase DE ROSA, 1955; ID., 1987; ID.1994.

5 Un análisis de las pandette del Banco dell'Annunziata durante los años 1588-89 no ha revelado cuentas registradas a nombre de Miguel Vaaz así como no hay pólizas a su nombre en los giornali copiapolizze del Banco di Santa Maria del Popolo durante los años 1589-90; la fragmentación de la documentación del Banco della Pietà durante los años comprendidos entre 1574 y 1609 no ha permitido un análisis sistemático de las pólizas relativas a este banco. En general parece que las primeras huellas de la actividad de Miguel Vaaz en los bancos Nápoles no son anteriores a 1592 .

6 SABATINI, 2010; ID. 2011; ID. 2012, HUERGA CRIADO, 2012. 
poles, en estrecha simbiosis con las elites del reino: la aristocracia, los letrados y el patriciado mercantil. En cuanto a este último, la relación con mercaderes y banqueros flamencos, españoles, portugueses, franceses, raguseos, venecianos y genoveses se explica, precisamente, a la vista de un creciente volumen de negocios que necesariamente requería interlocutores interconectados con las grandes plazas financieras y comerciales de Europa.

En este caso, las complejas vicisitudes que muestran al mercader judeoconverso protagonista de la escena política de la Nápoles española se han analizado con el auxilio de fuentes manuscritas conservadas en la Biblioteca Nazionale di Napoli. Se trata en concreto de un manuscrito anónimo titulado Michele Vais e le sue pregiudiziali invenzioni que contiene una larga y dura requisitoria contra la actividad de Vaaz durante los años del gobierno en Nápoles del virrey VII conde de Lemos, 1610-16167. La datación del manuscrito en 1616 permite adscribir su origen a la fase en la que, después del alejamiento del conde de Lemos de Nápoles, los enemigos de Vaaz, exponentes de la aristocracia del reino y de los banqueros genoveses en Nápoles, lanzaron una dura ofensiva contra el banquero judeoconverso que culminó en el intento de arresto realizado por parte del virrey duque de Osuna.

En cambio, constituyen una especie de memoria defensiva de su actividad las cartas enviadas en los años 1614-1615 por Miguel Vaaz al regente del Consejo de Italia en Madrid Juan Montoya de Cardona, durante un periodo de fuertes tensiones entre el virrey, conde de Lemos, y la aristocracia napolitana, tensiones a las que, como se verá, Miguel Vaaz, como consejero del virrey, no fue en absoluto ajeno ${ }^{8}$. Es oportuno señalar que, contrariamente a la documentación conservada en el Archivio Storico del Banco di Napoli, se trata en este caso de fuentes ya estudiadas, sobre todo por Isabel Enciso en su mo-

7 BNN, Manoscritti, X B 65, Michele Vais e le sue pregiudiziali invenzioni.

8 Las cartas de Miguel Vaaz se encuentran dentro de un legajo que contiene la correspondencia - de contenidos marcadamente políticos - mantenida en los años 1614-15 entre el virrey de Nápoles, el VII conde de Lemos, y Juan Montoya de Cardona, regente en el Consejo de Italia en Madrid: Carteggio del Reggente Montoya e del Conde de Lemos, BNN, Manoscritti Brancacciani, V B 10; concretamente se han utilizado dos cartas de Miguel Vaaz, con fecha de 8 de diciembre de 1614 y de 20 de mayo de 1615 (ibid, fls. 108r-v). Hay que hacer notar que en la misma fecha de la primera de estas dos cartas, hay también una extensa misiva del virrey: Carta de Pedro Fernández de Castro VII conde de Lemos sobre la oposición e apoyo a su gobierno (ibid, fls. 13r-21v), a la que se hará referencia. La historiografía no ha dedicado hasta ahora suficiente atención a la figura de Juan Montoya de Cardona, magistrado napolitano de origen español, desde 1591 consejero del Sacro Regio Consiglio, desde 1594 presidente de la Camera della Sommaria, desde 1611 regente de Cancillería y, en fin, desde 1613 regente en el Consejo de Italia en Madrid (INTORCIA, 1987: 228, 249, 345), a pesar de que haya muchas indicaciones de su importante papel político desarrollado en Nápoles en los años a caballo entre la primera y segunda década del siglo XVII, incluso como emisario de la familia del Papa Pablo V Borghese (METZLER, 2004). 
nografía sobre el VII conde de Lemos (2007: 383-409). Sin embargo, estas fuentes no se utilizan aquí para reconstruir la lucha entre las facciones políticas presentes en Nápoles al final del gobierno del conde de Lemos (ciertamente en estrecha relación con las análogas disputas en la corte de Madrid), sino para demostrar cómo las actividades comerciales y financieras de Miguel Vaaz estuvieron siempre en simbiosis con una estrategia de afirmación social y de un arraigo cada vez más fuerte en el poder político.

\section{COMERCIO E INTERMEDIACIÓN FINANCIERA}

\section{Miguel Vaaz mercader, banquero, armador}

La presencia de Miguel Vaaz en el reino de Nápoles se documenta a partir de 1585 , desde el momento en que se le paga regularmente un entretenimiento de 20 escudos al mes (aumentados a 30 desde 1586), por los servicios proporcionados durante la fase de consolidación de la unión de Portugal a la monarquía ${ }^{9}$. Las actividades que el mercader judeoconverso portugués desarrolló en la Italia meridional giraron siempre en torno a dos centros geográficos, la capital del reino, Nápoles, y las provincias de Apulia; con bastante frecuencia ambas áreas estuvieron vinculadas dentro de las mismas operaciones comerciales (sobre todo compra y venta de grano) o financieras, como el pago en Nápoles de letras de cambio que llegaban de Apulia o viceversa. Al mismo tiempo, Miguel Vaaz supo rápidamente ocupar un lugar relevante en el círculo de las familias de la aristocracia y del patriciado pullés, desempeñando importantes funciones de intermediación financiera de distinta naturaleza para numerosos miembros de éstas.

Para todas estas operaciones la letra de cambio fue indiscutiblemente el instrumento financiero más utilizado por Vaaz, quien transfería dinero desde y hacia las principales plazas comerciales y financieras pulleses, como Barletta, Manfredonia, Bari, Taranto, a menudo desde o hacia Nápoles, pero efectuaba también pagos en plazas de las limítrofes provincias abruzeses como Chieti, Lanciano, Tortoreto, tratándose siempre de lugares de producción o de

9 Al virrey de Nápoles de Alaminos a 6 de febrero de 1585. Entretenimiento de 20 escudos al mes en Nápoles a Miguel Vaez Portugués, AGS, Estado, leg. 1088, doc. n. 24; Acrecentamiento de 10 escudos el entretenimiento de 20 que Miguel Vaez tiene en Nápoles. En San [?] a primero de Agosto de 1586, ibid, doc. n. 165; la posición de entretenido de Miguel Vaaz viene así descrita en el memorial que constituye el principal acto de acusación contra el mercader judeoconverso «cotal nome hanno coloro che per lungo servizio o per altra degna opera traggono entrate dal fisco reale, che appo noi si chiamano altresì piazze morte» (Michele Vais e le sue pregiudiziali invenzioni en BNN, Manoscritti, X B 65). 
consumo de grano, o bien de puertos adriáticos vinculados a la navegación de cabotaje hacia Nápoles o Venecia.

Si las letras de cambio eran enviadas a plazas fuera del reino de Nápoles, los destinos más frecuentes eran Roma, Florencia o Venecia, aunque no faltaban transferencias de dinero destinadas a las ferias de cambio de Piacenza. En estos casos la suma enviada o recibida era expresada en scudi di marco, que era la unidad de cuenta utilizada en la feria, con la indicación del tipo de cambio operado en los mercados extranjeros en relación al ducado napolitano ${ }^{10}$. Un ejemplo de estas operaciones es el envío, en 1605, por parte de Miguel Vaaz al banquero francés Jacques Tavére de Lyon, de una letra de cambio pagadera a la compañía de Charles Baile y socios, por un importe de 4.662 escudos de oro de Francia del valor de tres liras tornesas cada escudo, con un tipo de cambio aplicado de 131 escudos de oro de Francia por cien ducados de oro napolitanos ${ }^{11}$. En un caso análogo, en 1601 Miguel Vaaz enviaba una letra de cambio a Roma para completar la transferencia de una suma desde Palermo, que se cambiaba a razón de 120 tarì de moneda siciliana por un ducado de oro napolitano ${ }^{12}$. En general, son frecuentes las letras de cambio enviadas por el mercader judeoconverso para pagar las nada exiguas rentas feudales o eclesiásticas de las que residentes en Roma gozaban en el reino de Nápoles ${ }^{13}$.

Entre las letras de cambio que llegan a Miguel Vaaz desde las plazas externas al reino, se pueden recordar a modo de ejemplo las tres que en el transcurso de 1607 fueron enviadas por Melchiorre Noirot de Venecia, destinadas a los mercaderes flamencos residentes en Nápoles Giovanni Battista Schoemacher y David Vanderpiet, y a la compañía Möen y Reynart, esta también activa en la capital del reino ${ }^{14}$. Entre 1605 y 1607 se pagaron cuatro letras de cambio que procedían de renombrados mercaderes florentinos, entre ellos los Salviati, los hermanos Lorenzo y Francesco Melchiorre, y Filippo Capponi asociado con Francesco Purro. Otras letras provenían de España y se referían

\footnotetext{
2008.

${ }^{10}$ Sobre el sistema de las ferias, incluso para una extensa bibliografía, véase MARSILIO,

${ }^{11}$ Véase por ejemplo A Michele Vaez 14/07/1605, ASBN, Banco San Giacomo, giornale copiapolizze.

12 En diciembre de 1601 Miguel Vaaz pagaba 1.500 ducados a Cesare Zattera por el dinero que el genovés había enviado a Roma, para completar la trasferencia, realizada con cinco letras de cambio, de una suma que en total ascendía a casi 2.270 ducados: A Cesare Zattera 12/12/1601, ASBN, Banco San Giacomo, giornale copiapolizze.

${ }^{13}$ Sobre los problemas que la salida de moneda de Nápoles para pagar rentas, sobre todo en Roma y Génova, causaba a la balanza de pagos del reino véase DE ROSA, 1987.

${ }^{14}$ A Michele Vaez 26/10/1607, ASBN, Banco Spirito Santo, giornale copiapolizze.
} 
al armamento de navíos o a otras operaciones comerciales; en este caso la divisa con la que se emitían las letras de cambio era el real castellano ${ }^{15}$.

Veamos más detalladamente algunas de las operaciones efectuadas por Vaaz en referencia a las provincias pullesas: desde el principio de los años 90 realiza pagos y cobros para Adriano Acquaviva, el poderoso conde de Conversano, señorío ubicado en la provincia de Terra di Bari; en nombre del conde de Conversano, por ejemplo, el 9 de agosto de 1593 Vaaz paga 250 ducados al capitán Giovanni de Vedoia, ocupado en las operaciones de persecución del bandido Orazio De Antonellis ${ }^{16}$. En los mismos años, Vaaz opera regularmente para transferir a Nápoles, en las arcas reales, sumas recaudadas en las plazas pulleses, así por ejemplo, en 1595 efectúa una transferencia de 200 ducados por cuenta del Gobernador de Otranto, Gaspare Tamaio, y otra en relación a la adquisición de un impuesto de 6.000 ducados con un tipo de interés del 7\% sobre los ingresos de la aduana de Barletta ${ }^{17}$.

Entre las familias del patriciado pullés con quienes Miguel Vaaz establece estrechas relaciones sobresale la familia de los Santacroce, originaria de la ciudad de Barletta, uno de los más activos puertos comerciales de la zona. Se trata de una familia que ostenta un antiguo linaje, aunque no adscrito a la nobleza urbana, pero que desarrolla diversas actividades de tipo comercial, vinculadas sobre todo al comercio de los cereales; lo atestigua, entre otras cosas, un pago de 7.000 ducados que Miguel Vaaz efectúa a Dianora Santacroce en 1603 por una carga de grano; en los mismos años, el mercader portugués salda en Nápoles diversas adquisiciones realizadas para la misma persona, entre ellas tejidos y pasamanerías, signo de una relación fiduciaria que concierne a varios ámbitos ${ }^{18}$.

Las operaciones que Miguel Vaaz desarrolla en estos años entrelazan continuamente la intermediación financiera, el comercio y el armamento de navíos mercantes; la creciente importancia de esta última actividad se atestigua por la adquisición en 1601 en el puerto de Nápoles de una nave de más de 2.200 salmas, equivalente a una capacidad de carga de aproximadamente 325 tone-

${ }^{15}$ A Quirze Pedrosa 03-12-1602, A Gio de Correa 31-01-1603, A Michele Vaez 25/02/1603, ASBN, Banco San Giacomo, giornale copiapolizze. En diciembre de 1602 Miguel Vaaz recibía 68 ducados de Quirze Pedrosa por la suma pagada en Barcelona en virtud de una letra de cambio «sopra corpo et nolito per la sua ispedizione della sua nave». En febrero de 1603 el portugués paga al capitán Cristóbal de Bustos 158 ducados por la suma pagada a Simón Vaaz Enríquez, destinada al caballero de la orden de San Juan, Simón de Miranda Enríquez.

${ }^{16}$ A Michele Vaez, 09/08/1593, ASBN, Banco Spirito Santo, giornale copiapolizze.

${ }^{17}$ A Gio Batta e Gio Jacobo Noris 15/06/1595, ASBN, Banco Spirito Santo, giornale copiapolizze.

18 A Michele Vaez 31/08/1601 y A Michele Vaez 02/01/1603, ASBN, Banco San Giacomo, giornale copiapolizze. 
ladas, para un armador griego, originario de la isla de Lindos, al precio de 4.000 ducados $^{19}$.

La documentación de los bancos napolitanos indica claramente que para sus actividades comerciales Miguel Vaaz mantiene un número extraordinariamente alto de contactos con capitanes de navíos y otros armadores extranjeros, lo que, como se ha demostrado en otra parte, hay que relacionar con el desarrollo de actividades de navegación corsaria ${ }^{20}$. Entre los capitanes de los navíos utilizados por Vaaz para el transporte del grano y de otras mercancías estaban los raguseos Marino de Francesco Radulovich, Piero de Marco Rasich, Marco Stanich, Vincenzo Stalich de Curzola; el flamenco Pietro d'Orange, los franceses Bartolomé y Joseph d'Antibes y Honoré Carbonell. Este último era beneficiario, en abril de 1603, de un pago de 38 ducados y medio que Miguel Vaaz destinaba al socio Cesare Zattera para cerrar la cuenta que tenían pendiente con el capitán francés, propietario de un navío que Vaaz y Zattera habían utilizado para alcanzar Nápoles. El pago se efectuó con una letra de cambio en moneda de 35 escudos de 12 tarì por escudo pagado al capitán francés por Cipriano y Raffaele Carso de la ciudad de Tropea en Calabria ${ }^{21}$.

Entre los socios de Vaaz para la carga del grano en Barletta estaba el español Pedro Núñez de Santander, quien en 1601 había embarcado por cuenta del banquero portugués 568 carra de grano, equivalentes a 20.448 tomoli $^{22}$. Las relaciones con Santander se intensificaron entre enero y abril de 1603 cuando Miguel Vaaz recibió 1.000 ducados de María de Mendoza, a cuenta de los que el portugués debía pagar en España a Alonso de Mendoza, primo de María, por orden del capitán Pedro Núñez de Santander. En estas y otras transacciones Vaaz actuaba como intermediario entre Pedro Núñez de Santander y varios miembros del linaje de los Mendoza, transfiriendo dinero entre Italia y España $^{23}$.

${ }_{19}$ A Michele Vaez 19/10/1601, ASBN, Banco San Giacomo, giornale copiapolizze.

20 SABATINI, 2011: 148-151.

${ }^{21}$ A Michele Vaez 26/04/1603, ASBN, Banco Spirito Santo, giornale copiapolizze. Los pagos a los capitanes o a los armadores de los navíos de los que Vaaz se servía para sus actividades comerciales eran frecuentes y servían por su «galione» (a Geronimo di Scala y Pietro Larboro por los gastos sostenidos y por los servicios ofrecidos hasta el 23 de julio de 1607, $A$ Michele Vaez 24-7-1607, ASBN, Banco Santo Spirito, giornale copiapolizze) o por los «noliti» (al capitán Guglielmo Corentena por el flete de su navío que transportaba grano desde los Abruzos a la capital, A Michele Vaez 02-12-1603, ASBN, Banco Spirito Santo, giornale copiapolizze).

${ }^{22}$ A Gio Andrea Preiyte e Zenobi Rustici 26/11/1601, ASBN, Banco San Giacomo, giornale copiapolizze.

${ }^{23}$ A diferencia de todos los demás, el pago del 10 de marzo era ordenado por el capitán Pietro Montemón de Santander y el pago del 26 de abril era efectuado a través de Geronimo Castagnola a Alonso de Mendoza por orden de Pietro Núñez. A Donna Maria de Mendozza 11/01/1603, A Donna Maria de Mendozza 07/02/1603, A Donna Maria de Mendozza 10/03/ 
Relaciones de negocios mantenía también con los acaudalados mercaderes flamencos Melchiorre Lovay y Giorgio Della Faille quienes comerciaban en Nápoles productos séricos y tejidos ${ }^{24}$ : en noviembre de 1601 los flamencos recibieron 1.500 ducados de Miguel Vaaz por el dinero que el mercader Giovanni de Vuole de Venecia había transferido a Nápoles a través del banquero judeoconverso ${ }^{25}$; en el mes de marzo siguiente Miguel Vaaz pagaba $226 \mathrm{du}-$ cados a los mismos mercaderes flamencos por la adquisición de 202 libras y 2 onzas de sedas crudas y otras telas ${ }^{26}$.

\section{El comercio del grano}

Dentro de las actividades comerciales de Miguel Vaaz, como ya se ha recordado, tiene un gran protagonismo el comercio del grano, ejercido sobre todo en el ámbito de la annona, el sistema de aprovisionamiento de la ciudad de Nápoles ${ }^{27}$. Aunque se trate de una actividad que realiza desde la llegada al reino de Nápoles, los primeros documentos que atestiguan el aumento del volumen de los negocios desarrollados por Vaaz en este ámbito se refieren a los años del gobierno en Nápoles de Fernando Ruiz de Castro, VI conde de Lemos, virrey de Nápoles entre 1599 y 1601, y de su hijo Francisco Fernández de Castro, lugarteniente general del reino en los años 1601-1603, figuras sobre las que volveremos más adelante.

En estos años Vaaz entró de forma estable en sociedad por una parte con Horatio Santacroce, mercader de grano y otros cereales, perteneciente a la ya recordada familia del patriciado de Barletta, y por otra con el mercader genovés Cesare Zattera. El vínculo con Santacroce constituía un canal privilegiado para el aprovisionamiento de grano en el área más rica de producción cerealista del reino, mientras que el vínculo con Zattera suponía la conexión con la importante red mercantil y financiera internacional, que pasaba por la república de San Jorge ${ }^{28}$.

1603, A Donna Maria de Mendozza 26/01/1603, ASBN, Banco Spirito Santo, giornale copiapolizze.

${ }^{24}$ Sobre el papel de los mercaderes flamencos en la economía napolitana véase NAPPI, 2000.

${ }^{25}$ A Michele Vaez 10-11-1601, ASBN, Banco San Giacomo, giornale copiapolizze.

${ }^{26}$ Ibidem; A Giorgio della Failla et Melchior Lovai 28/03/1602, ASBN, Banco Spirito Santo, giornale copiapolizze.

27 Sobre el sistema de la annona napolitana CONIGLIO, 1940; ID. 1941: ID. 1972; ALIFANO, 1996; FENICIA, 1996; PAPAGNA,1997; SABATINI, 1998a, 1998b, 2008.

${ }_{28}$ Para las controvertidos vínculos de Miguel Vaaz con la comunidad genovesa en Nápoles cfr. SABATINI, 2011. 
Vaaz se asoció con Horatio Santacroce para adquirir el grano en Apulia y enviarlo a Nápoles, donde el portugués estaba encargado de pagar letras de cambio enviadas por el mercader de Barletta para saldar la adquisición de las mercancías transportadas (por ejemplo, el 24 de septiembre de 1601 Miguel Vaaz pagaba a Gaspare Balsano, por orden de Santacroce, 246 ducados a cumplimiento de la compra de grano a un precio variable, según la calidad de la mercancía, entre 32 y 38 ducados por carro, que correspondía aproximadamente a 8 y 10 carlinos por tomolo ${ }^{29}$ ). Vaaz se servía también de Horatio Santacroce para negocios más al por menor; por ejemplo, en diciembre de 1603, recibió 38 ducados del consejero Giovanni Tommaso Salamanca para las compras que Horatio Santacroce había afrontado en Barletta por la adquisición y expedición de dos carra de cebada que ya habían llegado a Nápoles en el momento del pago ${ }^{30}$.

Por lo que respecta a Zattera, Vaaz importó para su contacto en Nápoles una primera cantidad de 95.719 tomoli de grano, por un valor total de 149.165 ducados $^{31}$; después, se introdujeron en la capital del reino en el transcurso del mismo año otros 20.000 tomoli de grano, por un total de 115.900 tomoli, adquiridos por la ciudad a precios oscilantes entre 15 y $15^{3 / 4}$ carlinos por tomo$l o$, considerados por los coetáneos muy ventajosos para los mercaderes ${ }^{32}$. Sin embargo, a causa de las carestías que se produjeron entre 1603 y 1605, los precios crecieron mucho más y en junio de 1605 el precio del grano había alcanzado los 23 carlinos por tomolo de grano de buena calidad, que Miguel Vaaz se complacía de haber depositado en los silos de Porta della Calce en Nápoles en una cantidad de mil tomoli ${ }^{33}$. Al mismo tiempo, el banquero portugués seguía vinculado a operaciones financieras de distinto tipo para procurarse el capital para el comercio del grano que desarrollaba asociado con Zattera. Por ejemplo, en el transcurso de 1601, Vaaz había hecho enviar y pagar a cargo de ambos socios, en las tres ferias desarrolladas en Piacenza, la considerable suma de 51.133 ducados, mientras que 124.973 ducados los había depositado en diferentes bancos públicos y privados, y 2.270 ducados habían sido enviados a Roma y Venecia con letras de cambio ${ }^{34}$.

El cada vez más vertiginoso y variado volumen de negocios desarrollado por Vaaz respecto a las actividades de comercio de grano se atestigua también por el uso que él hacía de formas de seguro de los cargamentos de trigo que

${ }^{29}$ A Michele Vaez 24/09/1601, ASBN, Banco San Giacomo, giornale copiapolizze.

30 Al consigliero Gio. Thomase Salamanca 09-12-1603, ASBN, Banco Spirito Santo, giornale copiapolizze.

${ }^{31}$ A Cesare Zattera 12/12/1601, ASBN, Banco San Giacomo, giornale copiapolizze.

${ }^{32}$ Ibidem.

${ }^{33}$ A Cesare Zattera 17/06/1605, ASBN, Banco San Giacomo, giornale copiapolizze.

${ }^{34}$ A Cesare Zattera 12/12/1601, ASBN, Banco San Giacomo, giornale copiapolizze. 
transportaba a Nápoles, lo que demuestra, entre otras cosas, el alto nivel de riesgo que estas empresas comportaban. En julio de 1602 un navío propiedad del francés Bartolomé d'Antibes, que transportaba desde Taranto a Nápoles un cargamento propiedad de Miguel Vaaz, fue primero asaltado por los turcos y luego interceptado por los venecianos, secuestrado por estos y adquirido por el superintendente de la armada de Venecia ${ }^{35}$. Gracias a la documentación relativa a este episodio, sabemos que el 30 de mayo de 1602 Miguel Vaaz había asegurado las mercancías que salían de Taranto por 200 ducados con los genoveses Cesare Zattera, Niccolò y Domenico Levanto, los cuales, en virtud del riesgo asumido, con sentencia del 4 de septiembre de 1602, fueron condenados por el consulado de la nación de Venecia, a pagar a Vaaz 200 ducados; de esta suma, el 8 de noviembre de 1602, los Levanto correspondían 150 ducados a Giovanni y Giulio Paceni de Génova a quienes, Vaaz había girado una parte del importe de la póliza de seguro ${ }^{36}$. En 1610 un navío propiedad de Giovanni Antonio Ceressi, en el que Vaaz había cargado grano, fue asaltado por los turcos y el cargamento resarcido gracias al seguro que el judeoconverso portugués había estipulado con Matteo Casapieri, Nicola d'Aragona y Andrea Bandeni, quienes pagaron 300 ducados por el reembolso de las mercancías, como se demuestra en las actas del consulado francés de Nápoles ${ }^{37}$.

La actividad de Miguel Vaaz se basaba también en la posibilidad de conseguir beneficios de los contratos de seguro, en el caso de que sus mercancías sufriesen daños a causa de naufragios o de otros posibles sucesos, como ataques de piratas, de corsarios, de turcos. En efecto, acusado de ser temerario en todas sus actividades, Vaaz no estuvo exento de la sospecha de haber cobrado el dinero previsto por el seguro de forma ilícita. Sin embargo, Vaaz no siempre lograba obtener todo el provecho que esperaba con las pólizas de seguros. Por ejemplo, durante el verano de 1604 dos navíos cargados de grano de propiedad de Miguel Vaaz, zarpados de Ancona en dirección a Nápoles, naufragaron, sufriendo daños tales que no pudieron alcanzar la capital del reino. Habida noticia de los naufragios, Vaaz, que había asegurado el cargamento, reclamó el resarcimiento previsto por el seguro. El primer navío, propiedad de Simone Moro, naufragó cerca de Mesina y el grano fue transportado y custodiado en la ciudad, como se establecía en la póliza de seguro registrada en el consulado genovés de Nápoles. Vaaz reclamaba el reembolso del cargamento de grano al precio previsto por la póliza pero en noviembre de 1604 los aseguradores Ambrosio Casella y Niccolò y Damiano Levanto, obtenida por la

35 A Cesare Zattara 24/10/1602, ASBN, Banco San Giacomo, giornale copiapolizze.

36 A Nicolò e Domenico Levanto 08-11-1602, ASBN, Banco San Giacomo, giornale copiapolizze. Sobre este episodio véase BARZAZI, 1991: 452; SABATINI, 2011: 150.

37 A Matteo Casapieri e Nicola d'Aragona e Andrea Bandeni 13/11/1610, ASBN, Banco San Giacomo, giornale copiapolizze. 
ciudad de Mesina la restitución del cargamento, procedieron a la venta del grano a un precio inferior del que se estimaba en la póliza de seguro y enviaron al banquero judeoconverso la suma correspondiente ${ }^{38}$.

También el segundo navío, propiedad del francés Francesco Loyer, sufrió graves daños durante el viaje y perdió una parte de su carga. En este caso, los aseguradores evaluaron el precio del cargamento del navío en base a la póliza de seguro que había sido registrada en el consulado de la nación francesa en Nápoles y obligaron a Vaaz a aceptar el reembolso del daño sufrido estimado de ese modo, renunciando a cualquier otra pretensión, incluso en el caso en que se hubiese llegado después a un procedimiento judicial. De este modo la pérdida de las mercaderías rentó a Miguel Vaaz solo 31 ducados, pagados por el asegurador Benedetto Benfante según una póliza que establecía en 100 ducados el valor total del cargamento ${ }^{39}$.

Si el pago de las pólizas relativas a los cargamentos de grano fue a menudo causa de disputas entre Miguel Vaaz y otros comerciantes y banqueros, el mercader judeoconverso tuvo también relaciones difíciles con los administradores de las aduanas del reino, a causa de los privilegios que había conseguido, por su posición dominante en el mercado financiero o gracias a las relaciones con el poder español. Por ejemplo, en el transcurso del primer semestre de 1602, más concretamente entre el 1 y el 13 de julio, Miguel Vaaz pagó al arrendatario de las aduanas de Apulia, Andrea Preyte, 1.378 ducados para los derechos de exportación del grano; sin embargo, se trataba de una cuantía de dinero bastante menor de la que a Vaaz le hubiera debido corresponder si no hubiese gozado del privilegio de pagar tales derechos en la medida reducida de un máximo de 5 carlinos por carro de grano, privilegio dura pero inútilmente impugnado por el arrendatario. En el segundo semestre de 1602 los derechos pagados por Vaaz ascendieron a 1.481 ducados, por un total de 2.859 ducados para todo el año, suma inferior a los derechos sólo pagados para el segundo semestre del año anterior y también en este caso considerada claramente inferior a la que le hubiera correspondido normalmente por las mismas cantidades de grano exportadas, con grave daño del erario y perjuicio para los arrendatarios de la aduana ${ }^{40}$.

${ }^{38}$ A Gio Ambrosio Casella, Nicolò et Domenico Levanto 4/11/1604, ASBN, Banco Spirito Santo, giornale copiapolizze. El seguro se suscribió en cantidad de 500 ducados por Giovanni Ambrosio Casella, Niccolò y Domenico Levanto y en 100 ducados más por Giovanni Ambrosio Livesi, sin embargo los aseguradores pagaron a Vaaz a título de resarcimiento por el daño sufrido 120 ducados. Sobre la actividad de los consulados en Nápoles, también en relación al ejercicio de funciones administrativas y judiciales, véase BRANCACCIO, 2001 y AGLIETTI, HERRERO SÁNCHEZ, ZAMORA RODRÍGUEZ, 2013.

39 Al rationale Ferrante Ametrano et Gio Andrea Preite 16/10/1604, ASBN, Banco Spirito Santo, giornale copiapolizze.

40 A Gio Andrea Preiyte e Zenobi Rustici 26/11/1601, ASBN, Banco San Giacomo, giornale copiapolizze. 


\section{Deuda pública y arrendamientos}

Además del comercio del grano, la otra gran actividad de Miguel Vaaz fue la especulación financiera realizada sobre la deuda pública napolitana y con el sistema de los arrendamientos, es decir, el sistema de gestión de los ingresos fiscales del reino - ya fuesen los impuestos pagados por las comunidades del reino o las gabelas y aduanas - que la real hacienda dejaba en manos de particulares a cambio de un porcentaje sobre la cantidad de dinero recaudada ${ }^{41}$. Por lo que se refiere a la deuda pública, la actividad de Vaaz era doble, por un lado actuaba como intermediario a la hora de encontrar los compradores - particulares, pero también instituciones eclesiásticas etc. - de la deuda emitida por los distintos órganos de la real hacienda; por otro, él mismo invertía en deuda pública y alimentaba el gran mercado de la especulación financiera napolitana.

Por lo que se refiere a su participación en el sistema de gestión de los ingresos fiscales del reino, desde 1602 se documentan los intereses de Miguel Vaaz en la aduana de Foggia, el tribunal que administraba el sistema de explotación de los pastos en Apulia, como demuestra el pago de 6.000 ducados efectuado en el mismo año por Octavio Grisignano al banquero portugués y a los demás oficiales de la aduana ${ }^{42}$. El pago fue realizado mediante letras de cambio dirigidas a Ottavio Grisignano y pagadas por Carlo D’Urso, además de pólizas del banco de los Spinola y del Monte de Piedad, y completado finalmente con un pago en efectivo de 31 ducados por parte del mismo Grisignano a Vaaz ${ }^{43}$.

A partir de 1604 se tiene noticia de inversiones más importantes del banquero portugués en el cobro de los derechos de salidas y entradas de los puertos del Adriático. Desde enero de 1604 Miguel Vaaz poseía una renta anual de 80 ducados sobre el arrendamiento de las aduanas de Apulia (75 ducados hasta $1603^{44}$ ) que le rentaba 27 ducados por cuatrimestre. De otra renta de 128 ducados anuales, que el portugués mantenía siempre de la aduana de Apulia, le fue pagada, por orden de la Real Cámara, una cuota equivalente a 295 ducados por los cinco meses desde el 5 de abril a finales de agosto de $1604^{45}$.

No menos importante fue la actividad de intermediación desarrollada como administrador de grandes patrimonios privados: en estos mismos años

${ }^{41}$ Sobre el sistema de los arrendamientos en Nápoles véase DE ROSA, 1958.

${ }^{42}$ Sobre el sistema de la aduana de Foggia véase MARINO, 1992.

43 Ad Ottavio Grisignano 24/09/1602, ASBN, Banco San Giacomo, giornale copiapolizze.

${ }^{44}$ A Michele Vaez 04/02/1603, ASBN, Banco San Giacomo, giornale copiapolizze.

${ }^{45}$ El 16 de octubre Miguel Vaaz recibía del racional Ferrante Ametrano y de Giovanni Andrea Preyte el pago de dos cuotas atrasadas por un total de 53 ducados: Al rationale Ferrante Ametrano et Gio Andrea Preite, 16/10/1604, ASBN, Banco Spirito Santo, giornale copiapolizze. 
Miguel Vaaz desempeñó el cargo de procurador para la administración de las rentas fiscales de Juan Alfonso Pimentel, conde de Benavente, quien sería entre 1603 y 1610, virrey de Nápoles; como su procurador, en 1602 el mercader judeoconverso recibió un pago de 130 ducados del regente de la Cancillería Pedro Castelletto, arrendatario de la gabela del vino en Nápoles, como pago por los meses de septiembre y octubre de 780 ducados anuales de renta que el conde de Benavente poseía sobre el arancel de esta mercancía ${ }^{46}$. En 1604, después del nombramiento de virrey de Nápoles, el conde de Benavente pasó a su hijo esta renta, que Vaaz continuó administrando ${ }^{47}$.

En abril de 1607, todavía como procurador de los condes de Benavente, Miguel Vaaz, recibía de Epifanio de Iubeno dos pagos de 195 y 933 ducados respectivamente, por intereses sobre la deuda pública obtenida capitalizando los ingresos fiscales de las comunidades del reino. El primer pago se refería a los intereses del tercer cuatrimestre de 1606 por 569 ducados colocados sobre las entradas fiscales de las comunidades de la Basilicata; el segundo por los intereses relativos a los meses de enero y febrero de 1607 por 300 ducados de capital puestos al $8 \%$ sobre la recaudación del donativo en curso aquel año ${ }^{48}$. Siempre como procurador, Vaaz efectuaba los pagos de los intereses a quienes habían prestado dinero a la real hacienda: por orden del virrey, Miguel Vaaz pagó por el primer cuatrimestre de 1604 a Anna de Espinosa 63 ducados como rendimiento de 3.000 ducados invertidos al $8 \%$ anual ${ }^{49}$.

La actividad de intermediación desarrollada por Miguel Vaaz se orientaba a muchos exponentes de las elites del reino. En el verano de 1603 se efectuaron dos pagos por parte del racional de la Camera della Sommaria, Claudio Bandito, a través de Dorotea Gioacchina, su mujer y su procuradora general, al regente de la Cancillería Bernardino de Barrionuevo. El pago se refería a los intereses devengados en 15 meses sobre 5.500 ducados invertidos en los ingresos recaudados por el donativo para las exenciones que se hacían en la provincia del Principato Citra. El dinero recibido por Barrionuevo fue enviado a Miguel Vaaz para que hiciera cuenta de los pagos que debía efectuar a Geronimo Serra y a otros ${ }^{50}$.

${ }^{46}$ A Pietro Castelletti protettore et Gio. Giacobo Dianese governatore, 01/06/1603, ASBN, Banco San Giacomo, giornale copiapolizze.

${ }^{47}$ Los administradores de la gabela del vino eran en 1604 Giovanni Battista Petra y Niccolò Radulovich: Gio Batta Petra e Nicolo Radulovich 18/08/1604, ASBN, Banco Spirito Santo, giornale copiapolizze.

${ }^{48}$ A Epifanio Iubeno 28-04-1607, ASBN, Banco Spirito Santo, giornale copiapolizze.

${ }^{49}$ La cuota pagada a Doña Ana de Spinosa comprendía el periodo desde el 30 de diciembre de 1603 al 4 de abril de 1604. Al rationale Ferrante Ametrano et Gio Andrea Preite 16/10/1604, ASBN, Banco Spirito Santo, giornale copiapolizze.

${ }^{50}$ Al Rationale Claudio Blandito 21/08/1603, ASBN, Banco Spirito Santo, giornale copiapolizze. 
Objeto de emisión de deuda pública, es decir, de capitalización de los ingresos y cesiones, era también el ius cavendi, es decir, el privilegio que el físco real ejercía sobre los ingresos provenientes de las gabelas de la ciudad de Nápoles para ser satisfecho antes que todos los demás acreedores, en razón de la prevalencia del interés público sobre el interés privado. El 19 de octubre de 1604 Miguel Vaaz adquiría con pacto de retroventa de Beatrice Orsini, con un traspaso a través del mercader genovés Cesare Zattera, 8.000 ducados de los ingresos provenientes del ius cavendi, con un rendimiento anual del $7 \% \%^{51}$.

Tres años después, a principios de 1607, los ingresos sobre el ius cavendi eran utilizados por Miguel Vaaz dentro de una compleja operación financiera en dos momentos que atañía primero a los banqueros Francesco D'Alessandro Guadagni y Aidolfo Giann y después a Lorenzo y Alessandro Strozzi. En la primera parte de la operación, Miguel Vaaz pagaba la considerable suma de 150.000 ducados a Francesco D’Alessandro Guadagni y Aidolfo Giann por las pólizas, créditos y remesas hechas a nombre de Vaaz sobre Venecia, Florencia, Piacenza y Amberes, y destinadas a Roberto Noirot de Amberes y Giacomo Valaer el joven, de Ámsterdam. Como garantía de la operación se habían utilizado entre otras cosas los ingresos del ius cavendi sobre las gabelas de la ciudad de Nápoles, capitalizadas a razón del 7\%. En el segundo momento de la operación, el capital de 8.000 ducados colocado sobre los ingresos del ius cavendi concurría a formar una cantidad de 50.000 ducados, que generaba siempre un rendimiento anual del 7\%, equivalente a 3.500 ducados. El dinero era transferido por Vaaz a sí mismo en nombre y con dinero efectivo de los Strozzi, quienes debían enviar una suma similar, por orden de Vaaz, a Giacomo Valaer el joven de Ámsterdam, con letras de cambio dirigidas a los socios de Amberes para efectuar pagos en nombre del banquero holandés ${ }^{52}$.

Miguel Vaaz actuaba por tanto como intermediario en el pago de letras de cambio por cuenta de acreditados miembros de la nobleza pullesa que utilizaban este instrumento financiero para el cobro de las rentas obtenidas por la administración de las comunidades de Foggia, Barletta, Bisceglie y Cerignola. Con este cargo Vaaz actuaba como agente de los Santacroce: en 1601 Horatio Santacroce, como representante del organismo municipal de Barletta, ordenaba a Vaaz que pagase a Giovanni della Rea y a su mujer Costanza Marullo 280 ducados por los intereses devengados en los primeros 5 meses del año sobre un impuesto de 3.000 ducados, que generaba un rendimiento del

${ }^{51}$ La retroventa estaba firmada por el notario Giovanni Battista Basso. A Donna Beatrice Orsina 19/10/1604, ASBN, Banco Spirito Santo, giornale copiapolizze. El pacto de retroventa es una cláusula incluida en un contrato de venta o que se le añade por medio de un contrato anejo por la que cualquiera que haya adquirido un bien está obligado a volver a transferirlo al vendedor utilizándose como garantía un préstamo que debe devolverse en determinado plazo.

${ }^{52}$ A Michele Vaez, 13/02/1607 e A Michele Vaez 15/02/1607, ASBN, Banco Spirito Santo, giornale copiapolizze. 
$7 \%$ anual. Igualmente, en diciembre de 1602 Antonio Santacroce, procurador de Giovanni della Rea para la administración de las comunidades de Barletta, Cerignola y Bisceglie, establecía que Miguel Vaaz dispusiese todos los pagos devengados durante el año como procurador del capitán español y de su mujer. Administrador de la comunidad de Foggia era en 1603 el regente Martos de Garastiola quien recibió de Vaaz 860 ducados a cuenta de los 1.093 ducados que debían pagarse por medio de una letra de cambio de Stefano Ambrosino por las rentas de 560 ducados anuales sobre un istrumento de 7.000 ducados, y de 240 ducados anuales por un istrumento de 3.000 ducados, ambos al $8 \%{ }^{53}$. La pericia de Miguel Vaaz fue empleada también cuando en 1610 Alonso de la Cueva y Benavides, miembro del consejo de su majestad y embajador en Venecia, ordenó efectuar un pago a los gobernadores del Banco San Giacomo de 3.000 ducados por una razón que se desconoce ${ }^{54}$.

\section{LA RELACIÓN CON EL PODER POLÍTICO}

\section{Productos de lujo para las elites del reino}

Miguel Vaaz fue comerciante de productos de lujo, entre ellos esclavos, vinos de alta calidad y tejidos preciosos ${ }^{55}$. En 1603, por ejemplo, adquirió de Fabio Staiano 22 toneles de vino campano Lacrima Christi a 15,5 ducados por tonel, mientras que en diciembre de 1602 estipuló un pacto de retroventa con Ferrante Bono de Nápoles, de 540 ducados anuales, con una tasa de interés del $9 \%$, por la compra de 285,3 cantara de lino de Aleppo y Fiume vendido a 22 ducados cada uno, por un total de 6.000 ducados $^{56}$. Fue probablemente mediante el comercio de objetos destinados a una clientela de altísimo rango, que los contactos vinculados a las prácticas de la intermediación financiera con los representantes de las elites del reino se reforzaron y transformaron para Vaaz en una extraordinaria red de relaciones sociales.

En este ámbito se debe probablemente incluir la relación con el linaje de los condes de Lemos, presentes en el reino más de un quinquenio; antes, en 1599-1601, con Fernando Ruiz de Castro Andrade y Portugal, VI conde de Lemos, virrey de Nápoles, y después de su muerte con el hijo menor Francisco Fernández de Castro Andrade y Portugal, conde de Castro, lugarteniente

53 A Michele Vaez 25/10/1601, A Michele Vaez 9/12/1602, A Michele Vaez 02/01/1603, ASBN, Banco San Giacomo, giornale copipolizze.

54 A Michele Vaez 20/12/1610, ASBN, Banco San Giacomo, giornale copiapolizze.

55 A Fra Vincenzo de Ponte 18/08/1601, ASBN, Banco San Giacomo, giornale copiapolizze.

${ }^{56} \mathrm{El}$ hemano de Miguel, Benedetto, mercader de bienes de lujo, adquirió entre $1601 \mathrm{y}$ 1616 telas de oro y medias. A Michele Vaez 04/01/1603 e A Michele Vaez 09/01/1603, ASBN, Banco San Giacomo, giornale copiapolizze. 
general del reino en 1601-1603 (y después VIII conde de Lemos) y por último con Pedro Fernández de Castro Andrade y Portugal, VII conde de Lemos, virrey de Nápoles entre 1610 y $1616^{57}$.

Los primeros miembros del linaje de los condes de Lemos con quienes se documentan relaciones de Miguel Vaaz son Catalina Zúñiga y Sandoval, mujer del VI conde de Lemos, su hijo Francisco de Castro y su nuera Lucrezia Gattinara de Legnano. También en este caso la compra de bienes de lujo se entretejía con operaciones financieras de distinta naturaleza: en 1602 Lucrezia Gattinara vendió a Lorenzo Stampa, a través de Vaaz, 1.578 piezas de tejidos preciosos blancos, llamados ciambellotti, desgravados de los derechos de aduanas, por un precio total de 13.453 ducados, pagados en parte con letra de cambio giradas en Lyon por un valor de 3.125 ducados $^{58}$. Al mismo tiempo, Vaaz administraba las rentas sobre las aduanas de Apulia pertenecientes a Francisco de Castro y a su mujer ${ }^{59}$. La condesa de Castro utilizaba también los servicios de Vaaz para el pago de las limosnas al monasterio de la S. Croce di Palazzo de los Padres Reformados de la orden de San Francisco; en 1603, el dinero ofrecido por Lucrezia Gattinara fue girado, con letra de cambio, para pagar al mercader Andrea Caserta que había comprado ocho cantara de lana para la confección de las vestiduras de los padres del monasterio ${ }^{60}$.

Particularmente intensas fueron las relaciones de negocios que Miguel Vaaz mantuvo con Francisco de Castro. Entre las operaciones que unieron a los dos personajes destaca un pago de 1.143 ducados que el 25 de octubre de 1601 Miguel Vaaz recibió de Andrés de Tovalina, secretario del conde de Castro, mientras que en abril de 1603 fue el secretario Tovalina quien ordenó un pago por cuenta de Vaaz ${ }^{61}$. En 1607 Francisco de Castro, al final de su mandato como lugarteniente general del reino, recibió de Miguel Vaaz 1.705 ducados en cumplimiento de 45.995 ducados que el mercader judeoconverso había cobrado en nombre del conde por varios pagos y emolumentos. Esta suma reunía los créditos y las deudas que Francisco de Castro debía cobrar o liquidar hasta el 20 de octubre de 1606, dejando al saldo en efectivo la diferencia. Entre los gastos se mencionaban los costos, que ascendían a 9.926 ducados, de objetos de plata, de paños y de otros artículos relacionados con el traslado del conde a Venecia como embajador del rey de España. Entre los créditos que quedaban para cobrar estaban la provisión del obispado de Lec-

57 Sobre el linaje de los condes de Lemos véase ENCISO ALONSO-MUÑUMER, 2007, y concretamente sobre Francisco Fernández de Castro FAVARÒ, 2013.

58 A Michele Vaez 07/01/1603 y A Michele Vaez 28/09/1610, ASBN, Banco San Giacomo, giornale copiapolizze.

59 A Ferrante Morfino 07/07/1605, ASBN, Banco San Giacomo, giornale copiapolizze.

${ }^{60}$ A Epifanio Iubeno 28/04/1603, ASBN, Banco Spirito Santo, giornale copiapolizze.

${ }^{61}$ A Andres de Tovalina 25/10/1601 y A Michele Vaez 03/04/1603, ASBN, Banco San Giacomo, giornale copiapolizze. 
ce, pagada por el Cardenal Guevara, que garantizaba 1.440 ducados durante tres años, 400 ducados que provenían de los arrendatarios del estado de Castro, como pago de 1.200 tomoli de cebada que habían sido enviados a la corte, y 137 ducados de la aduana de Foggia; quedaba también un crédito de 27.000 ducados sobre un rendimiento de 2.128 ducados al $7 \%$, que debía ser liquidado a Vaaz ${ }^{62}$.

El mismo esquema - compra de bienes de lujo y operaciones financieras - se repetiría con la llegada del VII conde de Lemos: en el 1610, el año del traslado del virrey a Nápoles y probablemente en relación con el nuevo cargo, Vaaz proveyó el pago de muchos productos de lujo - tejidos, paramentos, vestimentas y otros - que Pedro de Castro y su mujer, Catalina de la Cerda y Sandoval, compraron a comerciantes napolitanos, entre ellos Stefano de Felice, Francesco Romano y Giulio d'Avenia Bandaro ${ }^{63}$.

\section{Miguel Vaaz consejero del VII conde de Lemos: el enfrentamiento de 1614-1615}

En 1610 el reino de Nápoles salía de un ciclo de graves carestías que tuvieron su culmen en el bienio de 1604-1606 ${ }^{64}$. En estos años, tan difíciles para la población napolitana, el coste de la gestión de la annona de la ciudad había aumentado enormemente, tanto que el mismo conde de Lemos afirmaba en 1614 que durante los gobiernos de sus predecesores los gastos para el aprovisionamiento de la ciudad habían gravado el patrimonio del reino por más de 5.000.000 millones de ducados ${ }^{65}$, frente a ingresos anuales seguros estimados en 1612 en menos de 2.000.000 de ducados ${ }^{66}$.

Uno de los primeros actos de gobierno del conde de Lemos fue encargar la revisión de la administración del sistema de aprovisionamiento de Nápoles a Miguel Vaaz, quien en poco tiempo, como escribió más tarde el mismo virrey, evidenciando fraudes y formas de mala gestión, incrementó el patrimonio de la annona de casi 300.000 ducados a casi 550.000 ducados, prometiendo que si desde ese momento en adelante el cargo no hubiese sido dado a hombres inicuos y «descuidados» del bien de la comunidad, sino a un hombre capaz y

62 A Michele Vaez 26/02/1607, ASBN, Banco Spirito Santo, giornale copiapolizze.

${ }^{63}$ A Michele Vaaz 28/10/1610, ASBN, Banco San Giacomo, giornale copiapolizze.

${ }^{64}$ Cfr. CONIGLIO, 1955: 149-155; COLAPIETRA, 1972, vol. 5: 195-200; ZOTTA, 1978; DE ROSA, 1987: 71-88 e 110-127.

${ }^{65}$ Carta de Pedro Fernández de Castro, VII conde de Lemos, sobre la oposición y apoyo a su gobierno, Napoli, 8 de diciembre de 1614, BNN, Manoscritti Brancacciani, V B 10, 16 r-v.

${ }^{66}$ SABATINI, 2007a: 599. 
honesto como él, habría sido posible, con la ayuda de un gobierno experto, hacer que el patrimonio de la annona aumentase hasta un millón de ducados ${ }^{67}$.

Esta elevada opinión de Miguel Vaaz no era sin embargo compartida por todos, no solo por el modo desaprensivo con el que el banquero judeoconverso había procedido desde siempre en el mundo de los negocios, sino también por comportamientos que ahora comprometían directa y públicamente su relación con el conde de Lemos, como los medios con los que Vaaz había adquirido el señorío de Mola, sobre el cual, en 1613, el virrey había obtenido de Felipe III el título de conde para el mercader judeoconverso, o la calidad de grano vendida a la ciudad de Nápoles en los mismos años ${ }^{68}$. En otras palabras, con el proceder del gobierno del conde de Lemos en Nápoles, se instaura cada vez más claramente una distancia entre la fe casi ilimitada de la que Vaaz gozaba con el virrey, que lo elevó al rango de su principal consejero, especialmente en la gestión de los recursos económicos del reino y en la reforma de las instituciones financieras, y la hostilidad que esta privilegiada posición generaba en las elites dirigentes napolitanas, otros banqueros, sobre todo genoveses, y la aristocracia, en particular después de la concesión del rango de conde.

La hostilidad hacia Vaaz y la aversión generada por la consideración en que él era tenido por el virrey se manifestaron claramente en 1614-1615, en el enfrentamiento que se generó entre el conde del Lemos y la nobleza en materia de privilegios fiscales. Este acontecimiento, como se ha recordado y estudiado por Isabel Enciso en su monografía sobre el conde de $\operatorname{Lemos}^{69}$, se profundiza aquí solo por la parte que se refiere a Vaaz.

En 1614 el virrey pretendió unificar en el fisco real el cobro de los derechos de la aduana de Nápoles, hasta aquel momento divididos entre el fisco real y la ciudad. La medida promovida por el virrey no habría perjudicado a la ciudad, que habría continuado percibiendo la misma renta de la que gozaba anteriormente sin ocuparse directamente de la gestión de la aduana, pero perjudicaba directamente los intereses de cuantos invertían dinero en la compra del ingreso fiscal originado por el cobro de los derechos de la ciudad, es decir, de hecho, los intereses de la nobleza urbana ${ }^{70}$. La decisión de reunir la gabela de la entrada y salida de las mercancías de la ciudad de Nápoles en las manos del fisco era, en efecto, expresión del intento de hacer más eficiente la

${ }^{67}$ Carta del conde de Mola al regente Montoya, 20 de mayo de 1615, BNN, Manoscritti Brancacciani, V B 10, fls. 108r-v.

${ }^{68}$ Miguel Vais e le sue pregiudiziali invenzioni 1610-1616, BNN, Manoscritti, X 10 B 65; sobre ambos aspectos véase SABATINI, 2011.

${ }^{69}$ ENCISO ALONSO-MUÑUMER, 2007: 383-404.

${ }^{70}$ Carta de Pedro Fernández de Castro, VII conde de Lemos, sobre la oposición y apoyo a su gobierno, Napoli, 8 de deciembre de 1614, BNN, Manoscritti Brancacciani, V B 10, fl. 18r. Sobre el sistema de las aduanas del reino de Nápoles durante la edad española véase BIANCHINI, 1971: 257-261. 
administración fiscal en un momento en que la situación de la hacienda del reino de Nápoles era particularmente complicada; en efecto, el mismo conde de Lemos había declarado que, a su llegada al reino, había encontrado «il patrimonio reale tanto esausto e la città di Napoli tanto gravata di debito [che] di gran lunga l'esito avanzava l'introito» ${ }^{71}$.

Con la misma intención de aliviar las dificultades económicas del reino, había sido adelantada por el virrey una segunda propuesta que, en las intenciones del conde de Lemos, debía poner fin a la especulación inmobiliaria y al crecimiento descontrolado de la población de la capital, pero que fue también interpretada por parte de la clase aristocrática como un ataque ${ }^{72}$. En este caso el virrey había recuperado y aumentado las disposiciones ya existentes para la construcción de nuevas casas que no se adaptasen a las normas vigentes, estableciendo que, en el caso de que las prohibiciones no fuesen respetadas, serían impuestas multas, que en las expectativas del fisco debían asegurar a la hacienda un ingreso de al menos 100.000 ducados al año, pero, ya que los destinatarios de estas sanciones habrían sido sobre todo los grandes asentamientos nobiliarios del centro de la ciudad de Nápoles, también esta medida fue tachada de un espíritu antiaristocrático ${ }^{73}$.

Por último, casi contemporáneamente a estas dos medidas, el conde de Lemos tomó una tercera que hacía referencia al aprovisionamiento del agua a la ciudad de Nápoles, y concretamente a un manantial ubicado casi a ocho kilómetros al norte de la ciudad, en las tierras propiedad del monasterio benedictino de SS. Severino y Sossio. La ciudad había intentado comprar el manantial pero se lo impidió la intervención del Consiglio Collaterale, el máximo órgano de gobierno político del reino, presidido por el mismo virrey. No obstante, el Consiglio Collaterale prohibió a la ciudad el acuerdo con los monjes del monasterio pero consintió a la real hacienda llegar a un compromiso con los eclesiásticos si hubiese sido necesario para asegurar el aprovisionamiento de agua para la ciudad ${ }^{74}$.

Nótese que la propiedad del manantial en cuestión era fundamental para solucionar algunos de los problemas relacionados con el aprovisionamiento de pan de la ciudad, ya que el control de esta fuente de agua permitiría edificar en las proximidades de la ciudad nuevos molinos, que hubieran podido moler trigo hasta una cantidad de 5.000 tomoli al día, evitando así los peligros

${ }^{71}$ Miguel Vais e le sue pregiudiziali invenzioni 1610-1616, BNN, Manoscritti, X 10 B 65, fl. 3 .

72 Sobre el crecimiento demográfico de Nápoles entre finales del siglo XVI e inicio del XVII, y también con referencia a los problemas del aprovisionamiento, véase SABATINI, 1998.

${ }^{73}$ Carta de Pedro Fernández de Castro, VII conde de Lemos, sobre la oposición y apoyo a su gobierno, Napoli, 8 diciembre 1614, BNN, Manoscritti Brancacciani, V B 10, fl. 19r.

${ }^{74}$ BNN, Manoscritti Brancacciani, V B 10, fl. 20r. 
- pero también los fraudes y robos - relacionados con el transporte de grano a los molinos de otras localidades más alejadas, como Torre Annunziata, Scafati, etc. Además la ciudad había gastado para las obras de construcción del acueducto que habría canalizado el agua desde el manantial, más de 40.000 ducados, sin la participación del virrey y del Consiglio Collaterale, que ahora intervenían para impedir un acuerdo que ya se había alcanzado con los padres de SS. Severino y Sossio ${ }^{75}$.

La nobleza urbana, reunida en los Seggi, que representaban al organismo municipal de Nápoles, se sublevó y un grupo de aristócratas - que tenían intereses bien en la aduana, bien en la especulación inmobiliaria- guiados por Carlo Caracciolo y por el príncipe de Avellino, pidieron al virrey que desistiese de sus decisiones o que les concediera el permiso para que pudiesen llevar directamente a la corte, a Madrid, sus protestas. Aunque dispuesto a reconocer que en el asunto del agua las peticiones del fisco habían sido excesivas, el virrey, fortalecido además por el apoyo de algunos de sus más acreditados consejeros, entre ellos el regente de la Cancillería Fulvio Di Costanzo, marqués de Corleto, y el mismo Miguel Vaaz, decidió adoptar una posición extremadamente firme y en línea con la política adoptada en el asunto por el Consiglio Collaterale, negó la legitimidad de la petición del envío de la embajada a la corte. Los aristócratas disidentes, sin embargo, convocaron el 22 y 23 de agosto los Seggi y una vez obtenido el apoyo de una cincuentena de representantes del patriciado urbano, eligieron al duque de Bovino, Jerónimo de Guevara, para efectuar la embajada a la corte ${ }^{76}$. A su vez, el virrey reaccionó obteniendo de 108 representantes del patriciado urbano la firma de un documento que exigía detener inmediatamente la misión de Jerónimo de Guevara ${ }^{77}$.

${ }^{75}$ Sobre ordenación de los acueductos napolitanos a principios del siglo XVII y sus problemas de aprovisionamiento hídrico véase sintéticamente MONTUONO, 2008: 1038-1041, quien se sirve entre otros de un interesantísimo manuscrito anónimo napolitano, fechado alrededor de 1610, cuyo título es «El servicio de aguas en Nápoles» (BNM, ms 9610, fl.112r-115v).

${ }^{76}$ Carta de Pedro Fernández de Castro, VII conde de Lemos, sobre la oposición y apoyo a su gobierno, Napoli, 8 de diciembre de 1614, BNN, Manoscritti Brancacciani, V B 10, passim.

77 Jeronimo de Guevara era descrito por los partidarios de la misión diplomática como «persona di gran lignaggio, di segnalata virtù, versato in altre ambascerie per la sua religione a Roma, alla Magna alla maestà cesarea in Francia al Cristianissimo è stato causatore dell'elezione del suo Gran Maestro, ed in corte ben conosciuto, e con riscontro che egli ha con il segretario Baldarana per servitio fattogli in persona di suo figlio dell'istesso abito» (Miguel Vais e le sue pregiudiziali invenzioni, BNN, ms. X B 65, fl. 5r); a esta descripción elogiosa se opone aquella denigratoria que hizo Miguel Vaaz, quien en cambio insistía sobre el hecho de que Jerónimo era hijo de Iñigo de Guevara quien en el pasado había sido obligado a abandonar el reino por su postura contraria a la política del virrey y que él mismo era de naturaleza mercenaria, movido a cumplir la misión en Madrid a cambio del pago de quince o veinte mil ducados, circunstancia que contribuía a describir toda la operación como venal: Carta del conde de Mola al regente Montoya, 8 de diciembre de 1614, BNN, Manoscritti Brancacciani, V B 10, fls. 36v-37r. 
La protesta de los aristócratas, sin embargo, no estaba solo dirigida contra el conde de Lemos, sino también contra quien era considerado el inspirador de estos como de muchos otros actos del gobierno del virrey, Miguel Vaaz. Entre los distintos aspectos en los que los disidentes centraban la atención del virrey en el memorial en el que se pedía permiso para poder enviar la embajada a Madrid, estaba, en efecto, también la petición de que la administración de la real hacienda se confiase solo a los representantes de la ciudad y a los ministros del rey (es decir los propios aristócratas) y no a particulares, en concreto que de esta fuese excluido el conde de Mola, es decir, precisamente Miguel Vaaz:

que no se entremeta en administrar el peculio de la ciudad ninguna persona que tenga tratos y contratos, espacialmente el Conde de Mola, e que este gobierno se dexe a los Ministros de la Ciudad que asistan a él con intervención de los Ministros $\operatorname{regios}^{78}$.

Pero, ¿desde cuándo el conde de Mola había administrado con desenvoltura el dinero público? En la memoria escrita contra Miguel Vaaz se repasan las etapas de su acercamiento al conde de Lemos. Curiosamente no se recuerda la proximidad, que incluso parecía ser notoria, con otros miembros de la misma familia, pero se identificaba como intermediario con el virrey el lugarteniente de la Camera della Sommaria, Juan Alonso Suárez ${ }^{79}$. Suárez, que como vértice del principal tribunal administrativo del reino tenía también una responsabilidad directa en la gestión del patrimonio real, había presentado a Vaaz al conde de Lemos como «persona assai pratica ed intendente di voler anch'egli aiutar l'impresa» para ordenar y mejorar la gestión del reino ${ }^{80}$.

Por otra parte, era el mismo conde de Lemos quien deseaba cuanto antes afrontar la difícil situación del endeudamiento de la hacienda, «affinché il male non procedesse più oltre e cagionasse qualche sinistro accidente» ${ }^{81}, \mathrm{y}$ buscar la ayuda de los consejeros expertos: según lo que el mismo virrey escribió, los oficios del mercader judeoconverso le fueron aconsejados por el duque de Vietri, en su calidad de grasero en funciones, es decir, como el magistrado municipal encargado de la annona de Nápoles, y por su predecesor,

${ }^{78}$ Carta de Pedro Fernández de Castro, VII conde de Lemos, sobre la oposición y apoyo a su gobierno, Napoli, 8 diciembre 1614, BNN, Manoscritti Brancacciani, V B 10, fl. 15v.

${ }^{79}$ Juan Alonso Suárez, nombrado lugarteniente de la Camera della Sommaria en 1602, participó en este cargo a la visita de los oficios conducida por Juan de Herrera en los años de gobierno en Nápoles del conde de Benavente y fue posteriormente, por voluntad del conde de Lemos, nombrado regente del Consiglio Collaterale (CONIGLIO, 1955: 159; COMPARATO, 1974: 116; INTORCIA, 1987: 229, 384).

${ }^{80}$ Miguel Vais e le sue pregiudiziali invenzioni 1610-1616, BNN, manuscrito X B 65, fl. 3.

${ }^{81}$ Miguel Vais e le sue pregiudiziali invenzioni 1610-1616, BNN, manuscrito X B 65, fl. 3. 
el marqués de Corleto, quienes, habiendo conocido la nada común capacidad de Vaaz para aprovisionar de grano la ciudad, afirmaban que «todo lo que no es hallarse en Santo Lorenço con nosotros el Conde de Mola es perder tiempo», donde la referencia al monasterio de S. Lorenzo indica el lugar donde se reunía el organismo municipal napolitano, es decir los Seggi, y donde se resolvían por tanto los principales negocios de la administración de la ciudad ${ }^{82}$.

Una vez obtenida la confianza del conde de Lemos, Vaaz, según sus detractores, intentó desacreditar a Suárez ante los ojos del virrey, acusándolo, conforme avanzaba en la revisión de las cuentas, de haber hecho perder al erario 200.000 ducados por errores en la administración de los ingresos fiscales. De mismo modo se libró de otros opositores y forzó a todos los principales interlocutores del virrey a tratar con él los asuntos de estado:

usò così bello arteficio, che traendo alla sua volontà coloro, che per avventura egli conoscea di poter aiutare o opporsi ai suoi disegni, e qual non poté guadagnare in aspetto ponendo, non fu più mai chi gli applaudisse e lodasse i suoi trovati, non che gli argomentasse in contrario. [...] Et lui tutto il corteggio de' privati e de' signori, di lui tutte le sperienze e di offici e di ogni altro benché aspettassero dal viceré, a lui si comunicavano tutti i maggiori e più importanti negozi. Il che egli né ricusava, né mostrava di stimar molto, como che tutto ciò gli si dovesse ${ }^{83}$.

Las reformas en la contabilidad y en la administración financiera del reino que el conde de Lemos aplicó por sugerencia de Vaaz son bien conocidas ${ }^{84}$, cabe resaltar, sin embargo, como cada reforma llevaba consigo una dosis de descontento que terminaba a cargo del mercader judeoconverso. Por ejemplo, la creación de una Caja militar, destinada a racionalizar el pago de las milicias y apartada del control de la Tesorería general del reino, tuvo como inevitable corolario la hostilidad del tesorero general que vio en esta medida la causa de la disminución de la importancia de su propio cargo; del mismo modo, y siempre refiriéndonos a la creación de la Caja militar, para poner orden en el pago de los emolumentos a los militares del reino, era obligatorio que estos últimos denunciasen al fisco sus pagas anteriores, antes de que se le satisfaciesen las presentes, y también esta medida provocó resentimientos ${ }^{85}$. Además, la creación de la Caja militar no resolvió los problemas de financiación de la defensa del reino, que, a causa de la constante amenaza turca y del

${ }^{82}$ Carta de Pedro Fernández de Castro, VII conde de Lemos, sobre la oposición y apoyo a su gobierno, Napoli, 8 de diciembre de 1614, BNN, Manoscritti Brancacciani, V B 10, fl.16r.

${ }^{83}$ Miguel Vais e le sue pregiudiziali invenzioni 1610-1616, BNN, Manoscritti, X B 65, fl. $3 \mathrm{rev}$.

${ }^{84}$ GALASSO, 1994: 157-184; ENCISO ALONSO-MUÑUMER, 2007: 420-448; SABATINI, 2011: 155-157.

${ }^{85}$ BNN, Manoscritti, X B 65 fl. 3r-3v. 
sustento de las tropas en el Milanesado, continuó pesando en las arcas del Estado por más de 500.000 ducados, así que la hacienda se vio obligada a solicitar nuevos y más caros préstamos a los banqueros extranjeros ${ }^{86}$.

Paralelamente a las intervenciones sobre la máquina administrativa, Vaaz sugirió al conde de Lemos que procediese a una drástica reducción del gravamen sostenido por el Estado por la deuda pública, disminuyendo el tipo de interés correspondiente de forma aun más restrictiva de lo habitual, es decir sin dar la posibilidad a los suscriptores que no aceptasen la reducción del tipo de interés, de recuperar el capital invertido en la compra de la renta pública; esta medida suscitó una firme oposición de los poseedores de deuda pública, que lograron posteriormente obtener del soberano que no hubiese obligación de aceptar tal imposición ${ }^{87}$. En efecto, las elecciones en materia de venta de rentas vitalicias y, más en general, de deuda pública tenían importantes consecuencias en la estabilidad del reino y en su cohesión social; por lo tanto, la intervención del rey puede explicarse por el miedo a que las medidas tomadas por el virrey, al chocar con los intereses de la aristocracia napolitana, redujesen el consenso interno. Sin embargo, Vaaz, promotor de esta iniciativa, siguió apoyando la política de reducción de los tipos de interés, al considerar que, dada la pequeña proporción de deuda pública en manos de la nobleza local, el daño para los napolitanos habría sido muy limitado, mientras que las finanzas del reino hubieran conseguido una ganancia sustancial en relación a las rentas en manos de los banqueros extranjeros ${ }^{88}$.

Como indica la frase referida al duque de Vietri y al marqués de Corleto, ya antes de la llegada del conde del Lemos, Vaaz participaba informalmente en la administración municipal, es decir, concretamente, en la provisión de todas las mercancías comestibles (grassa), así como en el cobro de los ingresos de la ciudad (peculio), materias que, como se ha recordado, se trataban en una sala del monasterio, o tribunal, de S. Lorenzo. Una vez que se aseguró su proximidad con el virrey, esta función no pudo más que reforzarse: la presencia de Vaaz - no casualmente definido el «levito» de todo negocio- entre los administradores que trataban de la grassa y del peculio de la ciudad, se

${ }^{86}$ Carta del conde de Mola al regente Montoya, 8 de deciembre de 1614, BNN, Manoscritti Brancacciani, V B 10, fl. 38v; véase sobre esto SABATINI, 2007a.

${ }^{87}$ BNN, Manoscritti Brancacciani, V B 10 fl. 38v. CONIGLIO, 1955: 199; SABATINI, 2011: 157 .

${ }^{88}$ Vaaz en su memorial afirmaba que la reducción de los juros habría pesado sobre el patrimonio de la nobleza napolitana sólo en 19.000 ducados, mientras que esta medida habría garantizado al Estado un ahorro de 95.000 ducados. Además, aceptando la renegociación de la deuda pública, la aristocracia habría accedido a la posibilidad de enajenar sus rentas, lo que de por sí se podía considerar una ventaja. Carta del conde de Mola al regente Montoya, 8 de diciembre de 1614, Manoscritti Brancacciani, VB 10, fl. 40r. Sobre la enajenación de la deuda pública en el reino de Nápoles en la Edad Moderna véase SABATINI, 2007 y y MANTELLI, 1997. 
convirtió en la norma y su opinión, aunque formalmente solo consultiva, era igualmente tenida en la máxima consideración, en primer lugar por el mismo virrey ${ }^{89}$. Quienes veían más fuertemente limitado su poder por la fastidiosa presencia del mercader judeoconverso era obviamente la antigua aristocracia de los Seggi, que tradicionalmente desde el organismo municipal gestionaba los recursos de la ciudad, claro está, no en su perjuicio.

Era, pues, este el contexto en el que, con la ocasión de la protesta de 1614 contra las medidas adoptadas por el virrey, había madurado el intento de enviar la delegación de Jerónimo de Guevara a Madrid y la petición al virrey para alejar a Vaaz de la gestión del dinero público. Por las cartas escritas al regente Montoya de Cardona sabemos en qué modo reaccionó Vaaz a las acusaciones contra su persona, aunque siempre bajo el declarado intento de ayudar al virrey. En primer lugar, Vaaz acusaba a los Seggi de haberse transformado de expresión del buen gobierno municipal en instrumentos de opresión, indicando que los representantes de la ciudad que se sentaban en ellos, eran sujetos sediciosos, que no actuaban por el bien común y al servicio del rey, sino inspirados por los propios intereses personales; para todos los Seggi, por lo tanto, Vaaz aportaba el elenco de los diputados elegidos, considerando que cada uno de ellos era «el más infame y de peor calidad y costumbre y de menor substancia ${ }^{90}$. En el asunto de la delegación de Jerónimo de Guevara, además, reconocía la responsabilidad de un reducido número de diputados - Carlo Caraza por el Seggio del barrio de Nilo, Muzio Carmignano por el Seggio del barrio de Montagna, Carlo Antonio Capace Zurlo por el Seggio del barrio de Capuana, todos considerados responsables de gravísimos delitosque habrían engañado a los otros diputados ${ }^{91}$.

Pero, sobre todo, Vaaz no dejaba de alabar la clarividencia política de su protector, cuya prudencia en el gobierno del reino había garantizado una prosperidad general, ya fuese en el aprovisionamiento de los productos alimentarios o en limitar los fraudes y la usura que enriquecían solo a negociantes y barones. Antes de la llegada del conde de Lemos -y por tanto implícitamente de su propia llegada - al gobierno de Nápoles, los especuladores del precio del grano obtenían beneficios muy altos, manteniendo artificialmente el precio del grano entre 25 y 30 carlinos por tomolo en las provincias, y entre 50 o 60 carlinos por tomolo en Nápoles, mientras que durante el gobierno del conde de Lemos los precios se establecieron entre 4 y 6 carlinos en las provincias y 10 y 12 carlinos en la capital, con una reducción de casi el $80 \%$, concluyendo que:

${ }^{89}$ Carta de Pedro Fernández de Castro, VII conde de Lemos, sobre la oposición y apoyo a su gobierno, Napoli, 8 de diciembre de 1614, Manoscritti Brancacciani, V B 10, fl. 19r.

${ }^{90}$ Carta del conde de Mola al regente Montoya, 8 de diciembre de 1614, Manoscritti Brancacciani, V B 10, fl. 33v.

${ }^{91}$ Carta del conde de Mola al regente Montoya, 8 de diciembre de 1614, Manoscritti Brancacciani, V B 10, fl. 33v. 
quanta es el alegría de los pueblos, es el dolor destos enteressados, añadiendo a esto la limpieça que ay en el Reyno de bandidos, la rectitud y igualdad en la justiçia, el ajustamento del patrimonio de la ciudad y universal ${ }^{92}$.

Mientras el desencuentro entre el virrey y la aristocracia municipal estaba todavía activo, en mayo de 1615 llegó la noticia del que el conde de Lemos no continuaría otro mandato en Nápoles y su partida se anunció para la mitad de 1616, lo que suscitó en Vaaz la no inmotivada preocupación de que esta decisión pudiese ser no solo la señal de la pérdida del favor del soberano hacia su propio representante, sino también el inicio del fin de su propia fortuna ${ }^{93}$. Las preocupaciones de Vaaz se mostraron más que justificadas porque la partida del conde de Lemos de Nápoles si por una parte resolvió muchas de las controversias que el virrey había suscitado, por otra aumentaría la presión sobre el mercader judeoconverso.

El memorial escrito contra Miguel Vaaz en 1616, poco antes o poco después del cambio de virrey en Nápoles, reflejó una especie de absolución póstuma de la obra del conde de Lemos, gran parte de cuyos errores eran ahora atribuidos al mercader judeoconverso, considerado «abusante e corrompente [la] bontà del conte». La lista de sus responsabilidades, por tanto, aumentó: además de la acusación de haber abusado de su influencia sobre el virrey y de haberse ilegítimamente reunido en el tribunal de San Lorenzo, manipulando hábilmente para fijar los precios de los productos alimentarios en su propio beneficio, Vaaz fue considerado culpable de la reducción del número de navíos que llegaban a Nápoles, así como de ejercer el monopolio del transporte y venta de las mercancías, que eran adquiridas en plazas extranjeras y revendidas a precios aumentados. Igualmente Vaaz fue acusado de obligar a los productores pulleses a ceder grano a un precio inferior al precio de mercado, para vender luego el producto en Nápoles obteniendo grandes beneficios; de este modo había conseguido eliminar la competencia, llegando incluso a hacer procesar con acusaciones falsas a Ascanio Delia, un rival de los negocios, que no había querido ceder a sus extorsiones ${ }^{94}$.

A causa de los actos engañosos de Miguel Vaaz «si son passati molti pericoli di risse e di tumulti» ${ }^{95}$, sostiene el anónimo autor del memorial de 1616, que se habían alterado los ánimos y se había dividido la nobleza en facciones,

\footnotetext{
${ }^{92}$ Carta del conde de Mola al regente Montoya, 8 de diciembre de 1614, Manoscritti Brancacciani, V B 10, fl. 34v.

${ }^{93}$ Carta del conde de Mola al regente Montoya, 20 de mayo de 1615, BNN, Manoscritti Brancacciani, V B 10, fls. 108r-v.

${ }^{94}$ Michele Vais e le sue pregiudizievoli invenzioni, 1610-1616, BNN, Manoscritti, X B 65, fl. 9r.

${ }_{95}$ Michele Vais e le sue pregiudizievoli invenzioni, 1610-1616, BNN, Manoscritti, X B 65 , fl. 13 r.
} 
contra todo buen ejemplo para el pueblo y con nefastas consecuencias para la ciudad. Aunque odioso a la mayoría, Vaaz, gracias a su poder económico, logró implicar en su causa no solo a «cavalieri, che per avventura gli stavan più vicini di affetto ${ }^{96}$, sino al mismo virrey, quien, en gratitud por el tesón que el banquero judeoconverso había prodigado en el cuidado de los asuntos del reino, se sintió obligado a defenderlo y «per aver servito lui si aveva concitati gli odi, poiché prima era amato o almeno non odiato $\rangle^{97}$.

Si el conde de Lemos sentía una obligación de reconocimiento con respecto a Vaaz, mayor era la deuda que tenían con él aquellos aristócratas que, dependiendo para su posición del virrey, no podían prescindir del favor de su más escuchado consejero, como el príncipe de San Severo «carico di debiti sino agli occhi ed interessato anch'egli nella materia de' grani», o el duque de Monteleone «obbligato alla casa di Lemos per tanti rispetti quanti ognuno sa», o en fin, Tiberio Carafa, «vedovo di donna Giulia Orsino, dalla quale conserva il titolo di principe di Bisignano, il vitto del quale dipende dall'arbitrio de' giudici e dal viceré e da altri» ${ }^{98}$.

La hostilidad contra Miguel Vaaz alcanzó su apogeo en los meses siguientes a la entrada en Nápoles del nuevo virrey y se saldó con la persecución que el duque de Osuna, en una posición opuesta respecto al conde de Lemos en la lucha entre facciones en la corte de Felipe III, libró contra todos los más estrechos colaboradores de su predecesor ${ }^{99}$. Entre estos no podía faltar Miguel Vaaz, de quien el duque de Osuna sospechaba que había intentado oponerse a su venida a Nápoles y quien precisamente en el momento de la llegada del nuevo virrey era nueva y públicamente acusado por el organismo municipal de haber vendido a la ciudad grano estropeado o de mala calidad ${ }^{100}$. El 4 de mayo de 1617, el virrey duque de Osuna ordenaba el arresto de Miguel Vaaz ${ }^{101}$.

\section{CONCLUSiOneS}

Mediante la lectura de las fuentes contables conservadas en el Archivio Storico del Banco di Napoli, se ha precisado no solo la tipología de los nego-

\footnotetext{
${ }^{96}$ Michele Vais e le sue pregiudizievoli invenzioni, 1610-1616, BNN, Manoscritti, X B 65, fl. $10 \mathrm{v}$.

${ }^{97}$ Michele Vais e le sue pregiudizievoli invenzioni, 1610-1616, BNN, Manoscritti, X B 65 , fl. $11 \mathrm{r}$.

${ }^{98}$ Michele Vais e le sue pregiudizievoli invenzioni, 1610-1616, BNN, Manoscritti, X B 65 , fl. $10 \mathrm{v}$.

99 Sobre el duque de Osuna véase LINDE, 2005, y sobre su gobierno en Nápoles SCHI-

PA, 1911 y COLAPIETRA, 1972: 201-208

100 ZAZZERA, 1846: 478-482.

${ }^{101}$ SABATINI, 2011: 159-161.
} 
cios de Miguel Vaaz, sino sobre todo las conductas de complicidad o conflicto con otros grupos mercantiles. La capacidad de moverse en diferentes niveles de inversión y la habilidad de manejar grandes cantidades de dinero no era, en efecto, ajena a otras categorías de agentes presentes en la plaza de Nápoles. Sin embargo, Miguel Vaaz logró aprovechar al máximo la capacidad de penetración en la red del gobierno español, que le permitió alcanzar la posición privilegiada de quien podía dirigir en su beneficio las decisiones del poder, no sin recurrir a medidas faltas de escrúpulos, como se evidencia por las numerosas acusaciones que recibió a lo largo de su carrera.

Este análisis, por tanto, delinea claramente y documenta algunas de las características de la figura de Miguel Vaaz: el número extraordinariamente elevado y diversificado de actividades de tipo comercial y financiero desarrolladas en Nápoles; su no menos extraordinaria capacidad de trabar relaciones con agentes locales y extranjeros en una multiplicidad de plazas dentro y fuera del reino; la progresiva capacidad de entrar en contacto con la elite del reino, primero con el patriciado mercantil de las ricas provincias de Apulia, lugar de producción y comercio de trigo, vino y aceite, y luego con la aristocracia y los banqueros de la capital; finalmente, y en estrecha conexión con los aspectos precedentes, la capacidad de aproximarse e incorporarse al poder español en Nápoles mediante los vínculos con el linaje de los condes de Lemos.

Sin embargo, no parece que estos cuatro aspectos deban ser analizados independientemente. Constituyen, en efecto, otros tantos elementos identificativos de una única estrategia de consolidación social y económica: uno servía para reforzar el otro y viceversa. Al mismo tiempo, la tupida red de relaciones que aseguró a Miguel Vaaz la obtención de riqueza y prestigio debe ser interpretada y aclarada dentro del complejo sistema de privilegios y posiciones ventajosas garantizados por la pertenencia al sistema policéntrico de la monarquía española. El estrecho vínculo que Miguel Vaaz mantuvo con los representantes de la corona en el reino de Nápoles permitió aprovechar al banquero judeoconverso las oportunidades que le ofrecía la administración del patrimonio regio. Del mismo modo, gracias a la capacidad de aprovechar en su propio beneficio el favor que le habían otorgado los virreyes, Vaaz llegó a hacer del comercio del grano, actividad con la que inició la creación de su propia fortuna, la base para otros y más remunerativos negocios y para conquistar un mercado en el que ya estaban arraigadas otras poderosas comunidades, como la de los genoveses residentes en Nápoles.

Todos estos elementos hacen de Miguel Vaaz una figura casi prototípica de mercader y banquero judeoconverso en un territorio de la monarquía española, en una relación simbiótica con el poder, que se configura sin embargo como un camino sin vuelta atrás: la hostilidad que de distinto modo numerosos exponentes de los grupos sociales dirigentes napolitanos - aristócratas, banqueros, poseedores de deuda pública - alimentaron hacia él, no podía 
sino llevar a una rápida caída en cuanto hubiese disminuido el apoyo político o cuando las circunstancias no permitiesen sustituir rápidamente un poder por otro, lo que en el caso de Miguel Vaaz, concretamente, sucedió a la partida del conde de Lemos de Nápoles, en 1616.

\section{BIBLIOGRAFÍA}

Aglietti, Marcella, Herrero Sánchez, Manuel, Zamora Rodríguez, Francisco (coords.), Los cónsules de extranjeros en la edad moderna y a principios de la edad contemporánea, Aranjuez (Madrid), Edición Doce Calles, 2013.

Alifano, Enrica, Il grano, il pane e la politica annonaria a Napoli nel Settecento, Napoli, ESI, 1996.

Barzazi, Antonella (coord.), Corrispondenze diplomatiche veneziane da Napoli. Dispacci (dal 27 maggio 1597 al 2 novembre 1604), Roma. Istituto Poligrafico e Zecca dello Stato, 1991.

Belli, Carolina, «Michele Vaaz 'hombre de negocios'», Ricerche sul '600 napoletano. Saggi e documenti, Napoli, Electa, 2000, 7-42.

Bianchini, Luigi, Storia delle finanze del Regno delle due Sicilie, edición a cargo de Luigi De Rosa, Napoli, ESI, 1971 (edición originale: Napoli 1859).

Brancaccio, Giovanni, «Nazione genovese». Consoli e colonia della Napoli moderna, Napoli, Guida, 2001.

Colapietra, Raffaele, Il governo spagnolo nell'Italia meridionale (Napoli dal 1580 al 1648), Napoli, Società Editrice Storia di Napoli, 1972: 161-278.

Comparato, Vittor Ivo, Uffici e società a Napoli (1600-1647), Firenze, L. S. Olschki, 1974.

Coniglio, Giuseppe, «Annona e calmieri nella Napoli spagnola», Archivio Storico per le Province Napoletane, LXV (1940), 105-194.

Coniglio, Giuseppe, «Note sulla storia della politica annonaria dei viceré spagnoli a Napoli», Archivio Storico per le Province Napoletane, LXVI (1941), 274-282.

Coniglio, Giuseppe, Il viceregno di Napoli nel sec. XVII. Notizie sulla vita commerciale e finanziaria secondo nuove ricerche negli archivi italiani e spagnoli, Roma, Edizioni di Storia e Letteratura, 1955.

Coniglio, Giuseppe, «L'Annona», en Storia di Napoli, V/II, Napoli, Società Editrice Storia di Napoli, 1972: 691-718.

De Rosa, Luigi, I cambi esteri del Regno di Napoli dal 1591 al 1707, Napoli, Banco di Napoli, 1955.

De Rosa, Luigi, Studi sugli arrendamenti del Regno di Napoli, Napoli, L'Arte Tipografica, 1958.

De Rosa, Luigi, Il Mezzogiorno spagnolo tra crescita e decadenza, Milano, Il Saggiatore, 1987.

De Rosa, Luigi (coord.), Il Mezzogiorno agli inizi del Seicento, Bari - Roma, Laterza, 1994. 
Enciso Alonso-Muñumer, Isabel, Nobleza, poder y mecenazgo en tiempo de Felipe III. Nápoles y el Conde de Lemos, Madrid, Actas editorial, 2007.

Favarò, Valentina, Carriere in movimento. Francisco Ruiz de Castro e la Monarchia di Filippo III, Palermo, Mediterranea - Studi e ricerche, 2013.

Fenicia, Giulio, Politica economia e realtà mercantile nel regno di Napoli nella prima metà del XVI secolo (1503-1556), Bari, Cacucci, 1996.

Huerga Criado, Pilar, «Cristianos nuevos de origen ibérico en el Reino de Nápoles en el siglo XVII», Sefarad, LXXII (2012), 351-387.

Intorcia, Gaetana, Magistrature del Regno di Napoli. Analisi prosopografica, secoli XVI-XVII, Napoli, Jovene, 1987.

Linde, Luis M. Don Pedro Girón, Duque de Osuna, la hegemonía española en Europa a comienzos del siglo XVII, Madrid, Encuentro, 2005.

Mantelli, Roberto, L'alienazione della rendita pubblica e $i$ suoi acquirenti dal 1556 al 1583 nel Regno di Napoli, Bari, Cacucci, 1997.

Marino, John, L'economia pastorale nel Regno di Napoli, Napoli, Guida, 1992.

Marsilio, Claudio, Dove il denaro fa denaro. Gli operatori finanziari genovesi nelle fiere di cambio del XVII secolo, Genova, Città del Silenzio, 2008.

Martini, Angelo, Manuale di metrologia ossia misure, pesi e monete in uso attualmente e anticamente presso tutti $i$ popoli, Torino, Loescher, 1883.

Metzler, Guido, «Clienti del papa, ministri del re. Le relazioni tra il cardinal nepote e ufficiali napoletani nel primo Seicento», en Betrand Fortclaz (coord.), Attori sociali e istituzioni in Antico Regime, número monográfico de Dimensioni e problemi della ricerca storica, 1/2004; 83-108.

Montuono, Giuseppe Maria, «L'approvvigionamento idrico della città di Napoli. L'acquedotto del Serino e il Formale Reale in un manoscritto della Biblioteca Nazionale di Madrid» [en linea], en Salvatore D'Agostino (coord.), Storia dell'Ingegneria. Atti del $2^{\circ}$ Convegno Nazionale, Napoli, 7-8-9 aprile 2008, Napoli, Associazione Italia di Storia dell'Ingegneria, 2008, vol. II: 1029-1050, disponible en: http: //www.aising.it/docs/ ATTI\%20II\%20CONVEGNO/1029-1050.pdf (consultado el 15 de abril de 2014).

Nappi, Eduardo, «Le attività finanziarie e sociali di Gasparo de Roomer. Nuovi documenti inediti su Cosimo Fanzago», Ricerche sul '600 napoletano. Saggi e documenti, Napoli, Electa, 2000: 61-92.

Papagna, Elena, «Napoli e le città del grano nel Mezzogiorno spagnolo», Società e storia, XX/75 (1997), 127-142.

Sabatini, Gaetano, «Carlo Tapia e le proposte di riforma dell'annona e delle finanze municipali nel regno di Napoli alla fine del XVI secolo», Storia Economica, I (1998a), 121-140.

Sabatini, Gaetano, «'Il pane di Cerbero'. Aspetti di politica annonaria e demografica nel Regno di Napoli nell'età di Filippo II », en José Martinez Millan (coord.), Felipe II (1598-1998). Europa y la Monarquia Catolica; I, Madrid, Editorial Parteluz, 1998b; 767-76.

Sabatini, Gaetano, «La spesa militare nel contesto della finanza pubblica napoletana del XVII secolo», Rossella Cancila (coord.), Mediterraneo in armi (secc. XVXVIII), Palermo, Quaderni di Mediterranea, 2007a; 593-635. 
Sabatini, Gaetano, «Nel sistema imperiale spagnolo: il debito pubblico napoletano nella prima età moderna», in Giuseppe De Luca e Angelo Moioli, Debito pubblico e mercati finanziari in Italia, secoli XII-XX, Milano, Franco Angeli, 2007b; 287-304.

Sabatini, Gaetano, «Carlo Tapia y el abastecimiento de grano en Nápoles», en José Martínez Millán y Maria Antonietta Visceglia (coords.), La monarquía de Felipe III, La Corte, vol. III, Madrid, Fundación Mapfre, 2008: 931-34.

Sabatini, Gaetano, «The Vaaz: Rise and Fall of a Family of Portuguese Bankers in Spanish Naples (1590-1660) », The Journal of European Economic History, XXIXX (2010); 623-655.

Sabatini, Gaetano, «Un mercato conteso: banchieri portoghesi alla conquista della Napoli dei genovesi (1590-1650)», en Manuel Herrero Sánchez, Yasmina Rocío Ben Yessef Garfía, Carlo Bitossi, Dino Puncuh (coords.), Génova y la Monarquía Hispánica (1528-1713), Genova, Atti della società ligure di Storia Patria, Nuova serie, vol. LI (2011); 141-170.

Sabatini, Gaetano, «From alliance to conflict, from finance to justice: a Portuguese family in Spanish Naples (1590-1660)», en Pedro Cardim, Tamar Herzog, José Javier Ruiz Ibáñez, Gaetano Sabatini (cords.), Polycentrics Monarchies, How Did Early Modern Spain And Portugal Achieve And Maintain A Global Hegemony?, Brighton, Sussex Academy Press, 2012; 91-107.

Scaramella, Pieroberto, «La campagna contro i giudaizzanti nel Regno di Napoli (1569-1582): antecedenti e risvolti di un'azione inquisitoriale», in Le inquisizioni cristiane e gli ebrei, Roma, Accademia Nazionale dei Lincei, 2003; 357-373.

Schipa, Michelangelo, La pretesa fellonia del Duca d'Ossuna (1619-20), Napoli, Pierro, 1911.

Sirago, Maria, «Due esempi di ascensione signorile: i Vaaz conti di Mola e gli Acquaviva conti di Conversano tra '500 e '600 (Terra di Bari)», Studi Storici Luigi Simeoni, XXXVI (1986), 169-213.

Sirago, Maria, «L'inserimento di una famiglia ebraica portoghese nella feudalità meridionale. I Vaaz a Mola di Bari (circa 1580-1816)», Archivio Storico Pugliese, XL (1987), 119-158.

Zazzera Francesco, «Giornali dell'Illustrissimo ed Eccellentissimo Signor Pietro Girone duca d'Ossuna», in Narrazioni e documenti sulla storia del regno di Napoli dall'anno 1522 al 1667, raccolti e ordinati con illustrazioni da Francesco Palermo, Archivio Storico Italiano, IX (1846), 471-617.

Zotta, Silvio, «Momenti e problemi di una crisi agraria in uno 'Stato' feudale napoletano (1585-1615)», Melanges de l'École Française de Rome, Moyen Age - Temps Modernes, XC/2 (1978), 715-79.

Recibido: $27 / 05 / 2014$

Aprobado: 29/12/2015 